\title{
Experimental Study of Square Inlets Effect on the Performances of Gas-Liquid Cylindrical Cyclone Separators (GLCC)
}

\author{
Ho Minh Kha ${ }^{1}$, Nguyen Thanh Nam ${ }^{2, *}$, Vo Tuyen ${ }^{3}$, Nguyen Tan Ken ${ }^{3}$
}

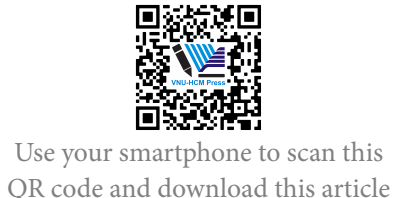

QR code and download this article

\begin{abstract}
In the gas-oil field, the gas-liquid cylindrical cyclone (GLCC) separator has potential replaced the traditional separator that is used over the century. It is also interesting for petroleum companies in recent years because of the effect of the oil world price. However, the behavior of phases in the equipment is very rapid, complex and unsteady which may cause the difficulty of enhancing the performance of the separation phases. The much research demonstrates that the geometry and the number of the inlet is probably the most important factor that impacts directly to the performance of separation of phases of the device. The main goal of the research paper is to deeply understand the effect of different geometrical configurations of the square inlet on hydrodynamics and performances for two phases flow (air-water). Two different inlet configurations are constructed, namely: One square inlet with the gradually reduced nozzle and two symmetric square inlets with the gradually reduced nozzle. As a result, the separation efficiency of the device will be higher when using two symmetric inlets and we suggest the application of two symmetric square inlets type that is the same angle of inclination and the area of the nozzle with the unique inlet configuration to improve separation efficiency in GLCC. Such inlet structure leads to lower swirl intensity decay than one inlet configuration. It also creates a more axis symmetric flow at the center line, which would improve the uplift of air bubbles in the performance of GLCC. Besides, this study can be viewed as a padding step to optimizing the operative parameters of GLCC in the further study.
\end{abstract}

Key words: Gas-liquid cylindrical cyclone separator, GLCC, cyclone separator, multiphase flow

\section{INTRODUCTION}

THE GLCC (Figure 1) consists of a vertical pipe with a tangential inclined inlet and outlets for gas and liquid. The tangential flow from the inlet to the body of the GLCC creates a swirl that produces centrifugal and buoyancy forces on the fluids that are an order of magnitude higher than the force of gravity. The combination of gravitational, centrifugal, and buoyancy forces separates the gas and liquid. The liquid is pushed radially outward and downward toward the liquid exit, while the gas is driven inward and upward toward the gas outlet. The low-cost, low-weight, compact GLCC separator offers an attractive alternative to the conventional separator which has been popularly used for this task, are large in size, bulky, and costly in purchasing and operating ${ }^{1-3}$.

The operational envelope of a GLCC is defined by two limiting phenomena: Liquid carry-over (LCO) in the gas stream and gas carry-under (GCU) in the liquid stream. The onset of liquid carry-over is identified by the first trace of liquid in the gas stream. Similarly, the first observable bubbles in the liquid underflow mark the onset of gas carry-under. The difficulty in devel- oping accurate performance predictions arises largely from the variety of complex flow patterns that can occur in the GLCC. The flow patterns above the inlet can include bubble, slug, churn, mist, and liquid ribbon. Below the inlet, the flow generally consists of a liquid vortex with a gas-core filament. Although, they have potential applications, complex phenomenon affecting the separating efficiency have not been studied completely in the past ${ }^{1-6}$.

This difficulty in predicting accurate the performance of the GLCC has been the single largest obstruction to the wide use of the GLCC. Even without tried and tested performance predictions, several successful applications of GLCC's have been reported ${ }^{3}$. The development of reliable performance-prediction tools will improve GLCC's through hardware modifications and, ultimately, will govern the speed and extent to which GLCC technology is deployed in existing and new field applications. Recent laboratory observations and computer simulations indicate that hardware modifications to the GLCC can have a profound effect on GLCC performance ${ }^{2}$. The GLCC performance is dependent upon the tangential velocities of

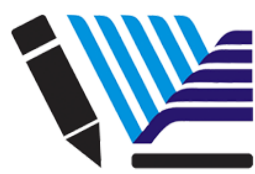

VNU-HCM Press
Cite this article : Kha H M, Nam N T, Tuyen V, Ken N T. Experimental Study of Square Inlets Effect on the Performances of Gas-Liquid Cylindrical Cyclone Separators (GLCC). Sci. Tech. Dev. J. Engineering and Technology; 2(SI1):SI127-SI136. 


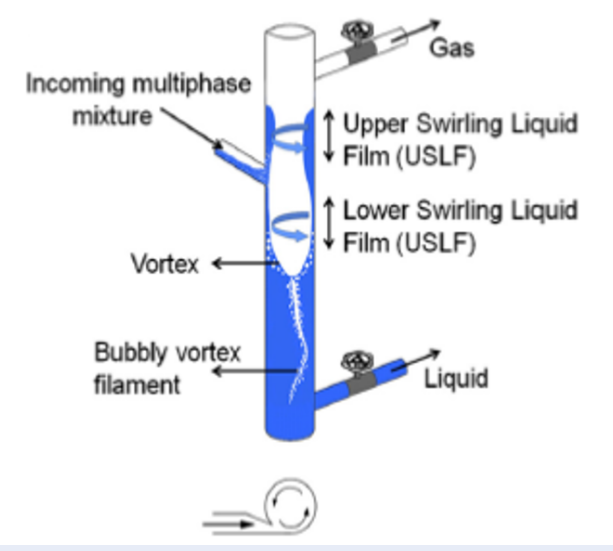

Figure 1: The Gas-Liquid Cylindrical Cyclone separator.

the swirling fluids, especially that of the liquid. The inlet is the single most redesigned component of the GLCC because of the inlet's influence on tangential velocity $^{1,2}$. Kouba and Shoham $(1996)^{1}$ observed experimentally that the optimal inclined inlet angle is $27^{\circ}$ which allowed to retard significantly the onset of liquid carry-over (LCO) in comparison with the horizontal inlet.

Most of the previous studies of GLCC separator were limited with the one inlet model ${ }^{7-10}$. Movafaghian et $\mathrm{al}^{11}$ researched the effects of geometry, fluid properties and pressure on the hydrodynamics of GLCC with one and two inlets. But the two inlets is the same of the side. Erdal et al ${ }^{12}$ studied two symmetric circular inlet models but the authors only analyzed with a liquid phase.

Recent studies propose the use of multiple tangential inlets to improve separation efficiency in GLCC. Such inlet configuration leads to lower swirl intensity decay than the unique inlet configuration. It also engenders a more axisymmetric flow, which would improve the GLCC performance with respect to $\mathrm{LCO}^{12-15}$. Thus far, over the past 22 years, more than 6500 GLCCs have been installed around the world by the petroleum and related industries ${ }^{16}$. However, the research has not been conducted on two symmetric inlet types to compare the effect of one type of inlet with the same angle of inclination and the area of the nozzle when it uses to separator multiphase.

\section{METHOD OF RESEARCH}

The GLCC' geometry is modeled size parameters along with experimental models of Hreiz. R et al ${ }^{13,14}$ (Figure 2). According to the diameter size of the pipe available on the market, in this investigation, two different inlet configurations (Figure 3 ) are constructed with the same inclined inlet is $27^{\circ}$ and the cross-sectional area of the inlet was approximately $28 \%$ compared to the cross-sectional area of GLCC. The two-phase mixture is introduced into the GLCC through a Y junction and the static mixer (Figure 4). The schematics of the GLCC test section shows in Figure 5. The experimental facility meets the following requirements:

- Two-phases (air-liquid), full separator.

- Easy and quick change of different inlet configurations.

- The GLCC body is transparent to allow visualizations and is manufactured in Acrylic

- The inlets are manufactured by stainless steel

- One phase, $1 \mathrm{HP}$ centrifugal pump, capable of producing 5-266 L/min (at the max head of 22 $\mathrm{m})$.

- One phase, 3 HP Ring Blower, capable of producing $325 \mathrm{~m}^{3} / \mathrm{h}$ (at the max head of $36 \mathrm{KPa}$ ).

- Two rotameters $\left(1.6-16 \mathrm{~m}^{3} / \mathrm{h}\right)$ and flow rate measurement tree to measure flow rates for different inlet configurations.

- One measures air flow

- A 120-liter storage tank

- Two static mixers 


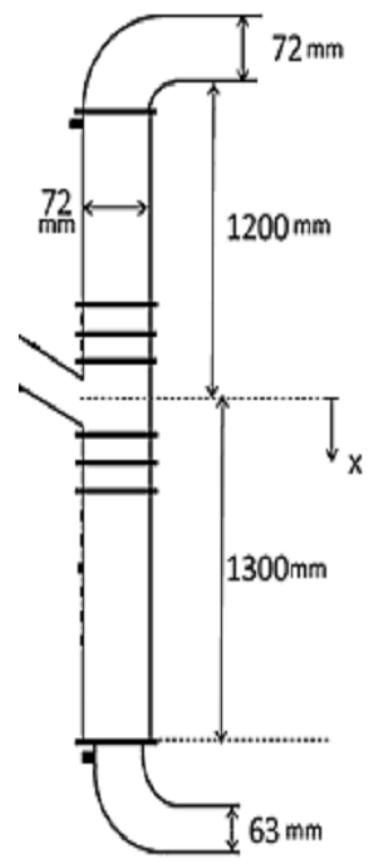

Figure 2: Main dimensions of the GLCC.

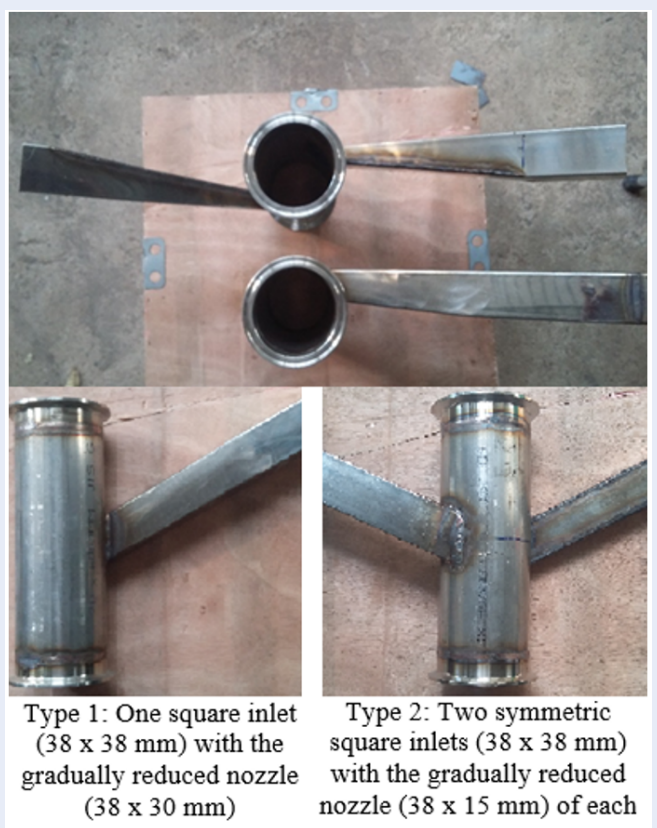

Figure 3: The different inlet configurations. 


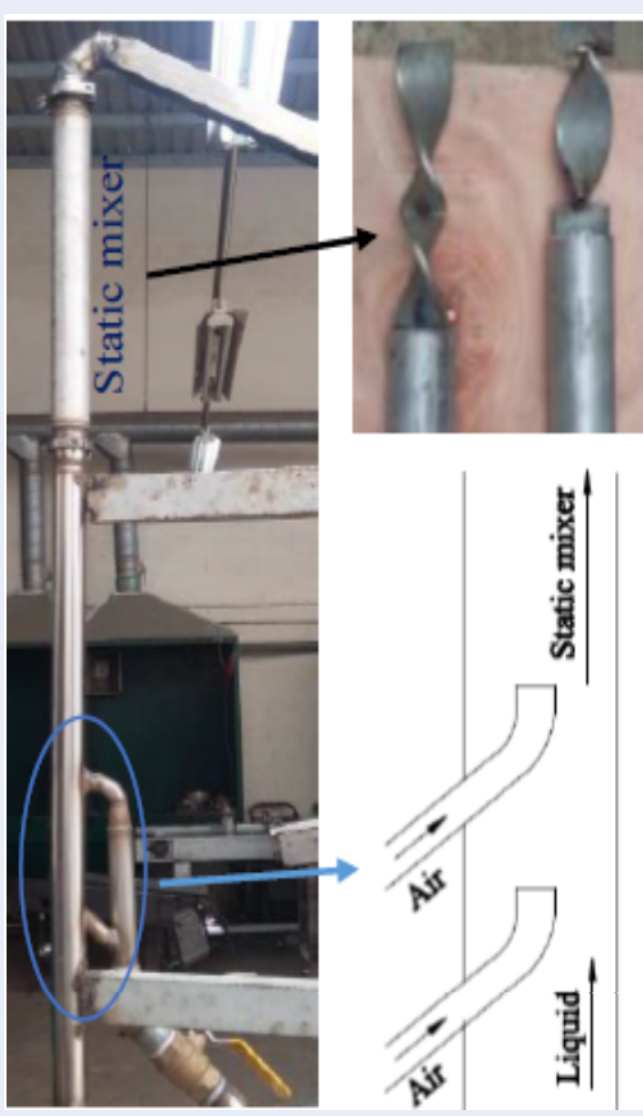

Figure 4: The $Y$ junction and static mixer.

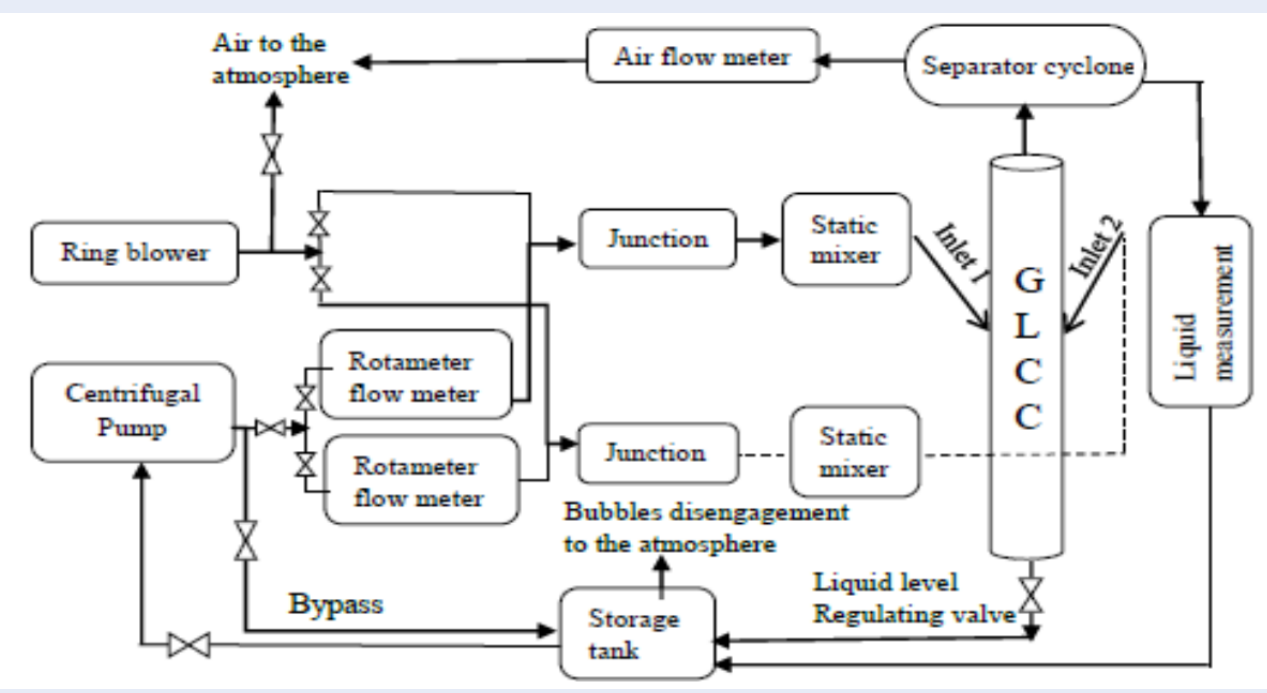

Figure 5: Schematics of the GLCC test section. 


\section{RESULTS}

In the GLCC upper part, liquid droplets are pushed toward the walls by centrifugal force and combine into a liquid layer. As this liquid layer is compact compared to discrete droplets, the gas flow will have more difficulties to take it up to the top outlet. The liquid from the wall layer falls down by gravity into the liquid vortex thereafter. However, if the gas flow rate is increased beyond a certain threshold, the liquid is carried over with the gas stream in the GLCC upper outlet. This limiting phenomenon is called Liquid CarryOver (LCO) ${ }^{14}$.

The LCO in the gas stream is largely dependent on the flow pattern in the upper part of the GLCC. Flooding may occur in the GLCC at high liquid levels and low gas rates, producing bubbly flow. The unsteady liquid fluctuations, characteristic of churn flow at moderate gas rates, may jump liquid into the gas outlet. The liquid can also be carried out in droplets at the onset of annular mist flow at high gas rates. At very high gas rates, the centrifugal force of the swirling gas pushes the liquid to the wall of the pipe, where it may form an upward-spiraling continuous ribbon of liquid ${ }^{1,2,17}$.

In our study, the GLCC is operated under conditions of LCO. When the superficial gas velocity in the cylindrical (Vsg) decreases from about $12.5 \mathrm{~m} / \mathrm{s}$ to about 1 $\mathrm{m} / \mathrm{s}$ and simultaneously, the superficial liquid velocity (Vsl) in the cylindrical increases from $0.1 \mathrm{~m} / \mathrm{s}$ to 0.62 $\mathrm{m} / \mathrm{s}$. The upper flow component of the GLCC also transitions from the annular flow to the flow churn (Figure 6) as the one inlet is used. However, when using the two-inlet type, the velocity value of Vsg and Vsl inside the cylindrical will be higher than the one inlet of the operational envelope of LCO. Effect of inlet geometry on the operational envelope for liquid carry-over (LCO) threshold are presented below.

Annular flow ${ }^{18}$ is a flow regime of two-phase gasliquid flow. It is characterized by the presence of a liquid film flowing on the channel wall and with the gas flowing in the gas core. The flow core can contain entrained liquid droplets. In this case, the region is often referred to as annular-dispersed flow, where the entrained fraction may vary from zero (a pure annular flow) to a value close to unity (a dispersed flow). Often both types of flow, pure annular and annulardispersed, are known under the general term of annular flow (Figure 6a).

The churn flow LCO regime the churning flow (Figure 6b) is a very chaotic and turbulent regime characterized by unstable vertical oscillations of the flow that can occur for moderate to high liquid flow rates. According to our visual observations, beyond a certain air flow rate, the USLF (Upper Liquid Swirling Film) is destabilized, mainly because of the air flow that tries to lift it up. Thus, the USLF loses its integrity, which results in a churn flow regime with violent oscillations just above the inlet level. Liquid droplets are ejected from the churn flow region and may splash up to the gas outlet, thereby initiating the LCO. If the gas flow rate is increased further, more liquid is lifted by the gas, and the churn flow regime invades all the upper part of the GLCC ${ }^{14,19}$.

With two symmetric inlets and when the GLCC is operated in a state of churn flow (Vsg $<4.5 \mathrm{~m} / \mathrm{s}$ and Vsl $>0.28 \mathrm{~m} / \mathrm{s}$ ). The flow in the upper of the GLCC fluctuates very strongly and continuously changes. It is characterized by the presence of a very thick and unstable liquid film, with the liquid often oscillating up and down in cycles (Figure 7). But, there is a really interesting which is the oscillation around the tube is relatively uniform when using the two inlet type compared to the other inlet. This will affect the performance of the separator.

In the GLCC lower part, if the swirl intensity is high enough, the free gas-liquid interface gets carved out and the vortex can be observed. The liquid flows from the inlet nozzle to the vortex in a thin swirling film (Figure 1), to which we will refer to as Lower Swirling Liquid Film, LSLF. Large bubbles quickly move toward the free interface due to buoyancy. Smaller bubbles, while being dragged downward by the liquid, are pushed radially toward the vortex center. They form a bubbly filament which allows a nice visualization of the vortex core. These bubbles are supposed to rise up to the free interface and to disengage ${ }^{1,14}$.

A variety of experiments has been conducted with the both of the inlets to investigate the different flow patterns in the lower part of the GLCC. The study was restricted to gas-liquid flow rates upper the LCO limit. The top part of the vortex, the crown, was maintained about $100 \mathrm{~mm}$ below the inlet nozzle through a valve installed on the GLCC lower outlet (Figure 8). The vortex level was not set closer to the entrance level for two reasons. The first reason is that in field conditions, gas and liquid flow rates fluctuate in time. Thus, the vortex level in the GLCC must be maintained at a certain distance from the inlet, so that the control system has enough time to react in the case of a sudden increase of the liquid flow rate, and prevents the vortex to exceed the inlet level and to lead to a precocious LCO. The second reason is that when the vortex level is too close to the entrance, we observed that the flow gets disrupted. As noticed by Shoham and Kouba $(1998)^{2}$, some distance from the entrance is necessary to achieve an optimal swirl intensity ${ }^{14}$. 


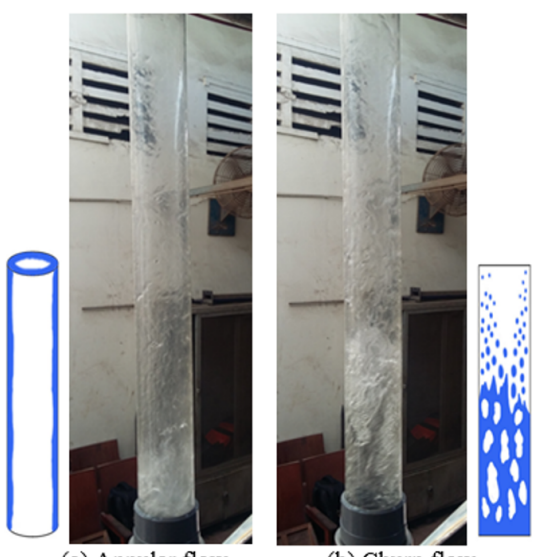

(a) Annular flow

(b) Churn flow

Figure 6: Schematics of different LCO flow regimes (Vsl $=0.341 \mathrm{~m} / \mathrm{s}, \mathrm{Vsg}=7.583 \mathrm{~m} / \mathrm{s})$.

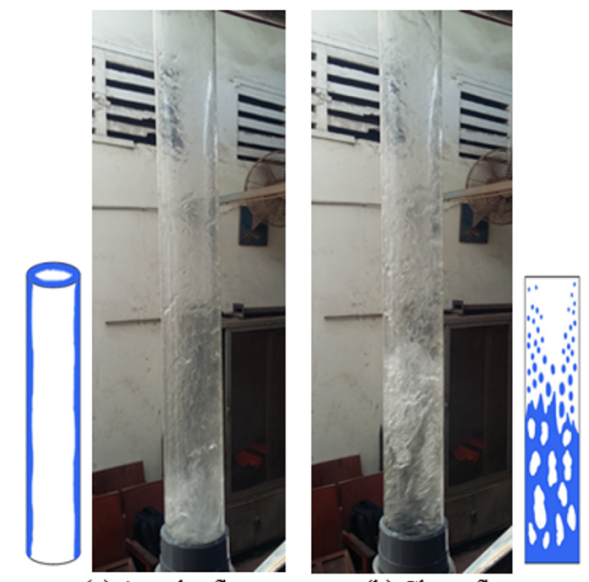

(a) Annular flow

(b) Churn flow

Figure 7: Fluctuations up and down in cycles of the churn flow LCO regime $(\mathrm{Vs}=0.41 \mathrm{~m} / \mathrm{s}, \mathrm{Vsg}=6.4 \mathrm{~m} / \mathrm{s}$ )

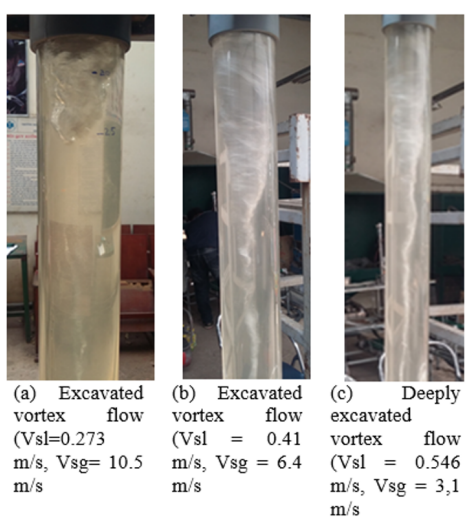

Figure 8: Different vortex regimes in the GLCC lower part (case type 2 is used). 
Figure 9 displays the filament core of a one and two circular inlets. The upward and downward flow region near the cylindrical center line for one inlet has a helical (spiral) shape. But, the upward and downward flow region near the cylindrical center line of two nozzle inlets is a quite axisymmetric flow field. In GLCC's design, this means that there is more space to capture bubbles at the center and uplift them to the gas-liquid interface for the separation.

\section{DISCUSSION}

A series of experiments is done at a fixed liquid flow rate. A gas flow rate is chosen, the mixture is introduced into the GLCC, and it is observed whether or not the liquid reaches the upper outlet to determine the start of liquid carry-over (LCO). Figure 10 shows the variations of the operational envelope for liquid carry-over (LCO) threshold with the GLCC inlet configurations, at atmospheric pressure for an air-water system.

Comparison between the present data and the data reported by Movafaghian et al $(2000)^{11}$ is presented in Figure 11. The comparison between the liquid carryover (LCO) operational envelopes for them reveals that the operational envelope of LCO expands significantly for the two symmetric inlets than the operational envelope of LCO for single-inlet. It demonstrates that the performance of the two symmetric inlets better than the performance of single-inlet for conditions approaching the operational envelope for LCO. In addition, when using this double inlet type is the working range is also significantly increased. Many experiments were conducted to compare the performance of GLCC, the top part of the vortex, the crown, was maintained about $100 \mathrm{~mm}$ below the inlet nozzle. The results show that the effect of structure and number of inlets has a clear impact on the performance of the separator. When using the two symmetric inlets type, the separation efficiency of liquid is higher than the one for the single inlet (Figure 12). From the graph shows that, when the corresponding liquid and gas velocities are shown in the graph, the phase separation efficiency of the symmetrical twoinlet type ranges from 92 to $95 \%$. Meanwhile, the phase separation efficiency of one inlet type is only about $85-88 \%$.

\section{CONCLUSIONS}

The operational envelopes for the liquid carry-over (LCO) of single inlet occur earlier than the one of the two symmetric inlet configuration. Besides, when using this double inlet type is the working range is also significantly increased.
The separation efficiency of the device will be higher when using two symmetric inlets. However, the manufacturing is more difficult and takes up more space than the other. In addition, the two-phase flow balance for the two inlets should also be considered.

Finally, we suggest the application of two symmetric inlets type that is the same angle of inclination and the area of the nozzle with the unique inlet configuration to improve separation efficiency in GLCC. Such inlet structure leads to lower swirl intensity decay than one inlet configuration. Besides, it also creates a more axis symmetric flow at the center line, which would improve the uplift of air bubbles in the performance of GLCC.

\section{LIST OF ABBREVIATIONS}

GLCC gas-liquid cylindrical cyclone

LCO Liquid carry-over

GCU gas carry-under

USLF Upper Liquid Swirling Film

LSLF Lower Swirling Liquid Film

\section{ACKNOWLEDGEMENTS}

This research is supported by DCSELAB and funded by Vietnam National University Ho Chi Minh City (VNU-HCM) under grant number C2018-20b-01. We appreciate highly the great support of DCSELAB which allowed and gave us a lot of facilities to perform the experiments and this paper.

The authors declare that all authors discussed the results and contributed to the final manuscript. There is no conflict of interest.

\section{REFERENCES}

1. Kouba, A G, Shoham O. Review of gas-liquid cylindrical cyclone technology. International Conference of Production Separation Systems, Aberdeen, UK. 1996;

2. Shoham O, Kouba GE. State of the art of gas/liquid cylindricalcyclonecompact-separator technology. SPE. 1998;2-5:462471.

3. Arpandi l, et al. Hydrodynamics of Two-Phase Flow in Gas/Liquid Cylindrical-Cyclone Separators. SPE Journal. 1996;427. Available from: https://doi.org/10.2118/30683-PA.

4. Gomez L, Mohan R, Shoham O, Marrelli JD, Kouba GE. Stateof-the-art simulator for field applications of gas-liquid cylindrical cyclone separators. SPE Annual Technical Conference and Exhibition, Houston, Texas . 1999;Available from: https: //doi.org/10.2118/56581-MS.

5. Erdal F, Shirazi S. Local velocity measurements and computational fluid dynamics (CFD) simulations of swirling flow in a gas-liquid cylindrical cyclone separator. Engineering Technology Conference on Energy, Texas. 2001;15:23-30.

6. Mohan R. Internal report. TUSTP. 2013;PMID: 23845670. Available from: https://doi.org/10.1136/bcr-2013-008665.

7. Hreiz R, Gentric C, Midoux N. Numerical investigation of swirling flow in cylindrical cyclones. Chem Eng Res Des. 2011;89:2521-2539. Available from: https://doi.org/10.1016/ j.cherd.2011.05.001. 


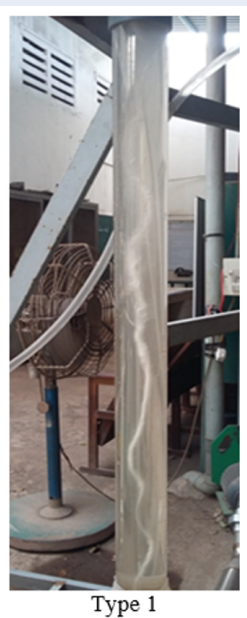

Type 1

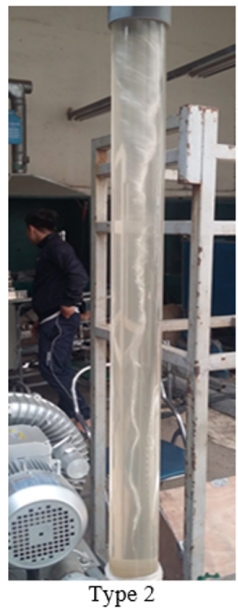

Type 2

Figure 9: The filament core in the GLCC lower part.

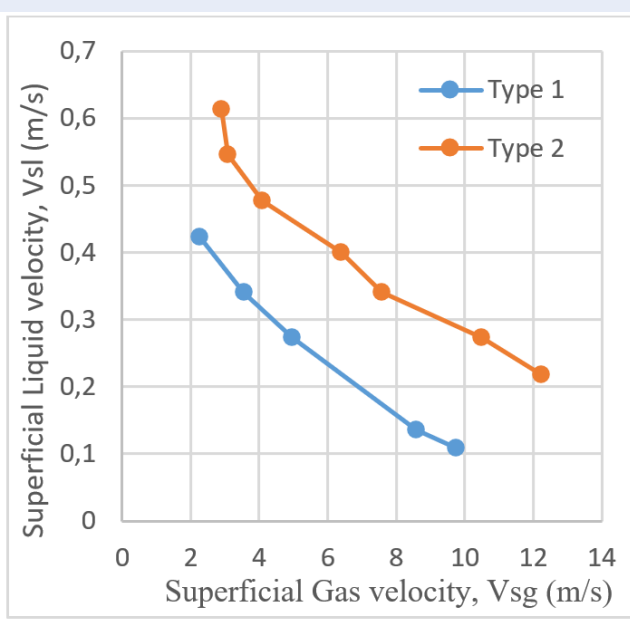

Figure 10: Effect of inlet geometry on the operational envelope for liquid carry-over (LCO) threshold.

8. Le V. Nghiên cứu động lực học dòng chảy trong bộ tách lọc dầu/khí GLCC. Tuyển tập công trình hội nghị khoa học cơ học thủy khí toàn quốc năm 2015. 2015;.

9. Kolla S, Mohan S, Shoham O. Experimental investigation of liquid carry-over in GLCC separators for 3-phase flow. IMECE2016-67457;p. V007T09A006. Available from: https:// doi.org/10.1115/IMECE2016-67457.

10. Le V. Influence of inlet angle on flow pattern and performance of gas-liquid cylindrical cyclone separator. Particulate Science And Technology ;Available from: https://doi.org/10.1080/ 02726351.2016 .1180336$.

11. Movafaghian S, et al. The effects of geometry, fluid properties and pressure on the hydrodynamics of gas-liquid cylindrical cyclone separators. International Journal of Multiphase Flow. 2000;26:999-1018. Available from: https://doi.org/10. 1016/S0301-9322(99)00076-2.

12. Erdal F, Shirazi S. Effect of inlet configuration on flow behavior in a cylindrical cyclone separator. ASME Eng Technol Conf on Energy. 2002;Available from: https://doi.org/10.1115/ ETCE2002/MANU-29110.
13. Hreiz R. Hydrodynamics and velocity measurements in gasliquid swirling flows in cylindrical cyclones. Chemical engineering research and design. 2014;Available from: https://doi. org/10.1016/j.cherd.2014.02.029.

14. Hreiz R, et al. On the effect of the nozzle design on theperformances of gas-liquid cylindrical cyclone separators. IntJ Multiphase Flow. 2014;58:15-26. Available from: https://doi.org/ 10.1016/j.ijmultiphaseflow.2013.08.006.

15. Ho M, Nguyen N, Nguyen T. The effect of different geometrical configurations of the performances of Gas-Liquid Cylindrical Cyclone separators (GLCC). System Science and Engineering (ICSSE). 2017;p. 646-651. Available from: https://doi.org/10. 1109/ICSSE.2017.8030955.

16. Kolla S. Structural integrity analysis of gas-liquid cylindrical cyclone (GLCC) separator inlet. Journal of Energy Resources Technology. 2018;140. Available from: https://doi.org/ $10.1115 / 1.4038622$.

17. Kataoka, Isao, Serizawa, Akimi. Bubble Flow. Available from: http://www.thermopedia.com/content/8/.

18. Zeigarnik, Albertovich Y. Annular flow;Available from: https://doi.org/10.1615/AtoZ.a.annular_flow;http: 


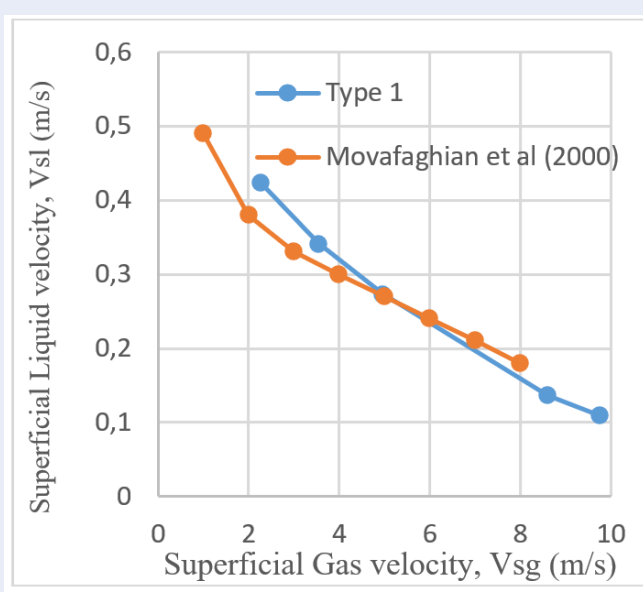

Figure 11: Comparison of the operational envelope for liquid carry-over (LCO) threshold ${ }^{11}$

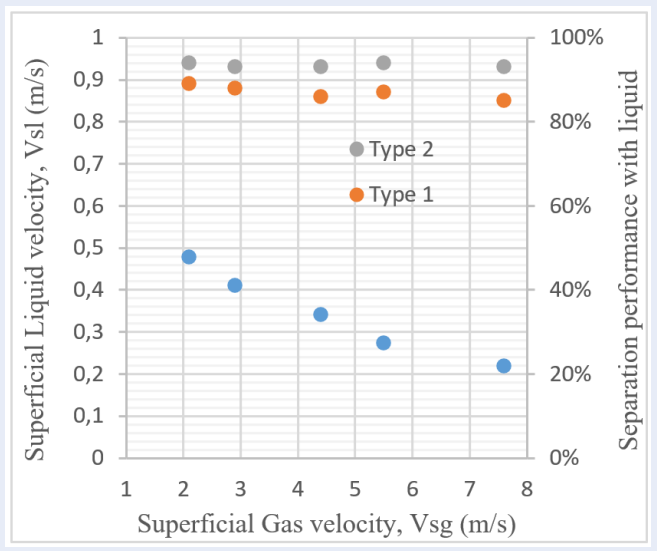

Figure 12: Separation performance with liquid. 


\title{
Nghiên cứu thực nghiệm về ảnh hưởng của đầu vào hình vuông ảnh hưởng đến hiệu suất của bộ tách lỏng-khí GLCC
}

\author{
Hồ Minh Kha ${ }^{1}$, Nguyễn Thanh Nam ${ }^{2}{ }^{*}$, Võ Tuyển ${ }^{3}$, Nguyễn Tấn Ken ${ }^{3}$
}

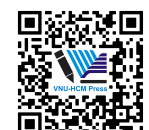

Use your smartphone to scan this QR code and download this article

\section{TÓM TẮT}

Trong lĩnh vực dầu khí, thiết bị tách khí-lỏng GLCC có tiềm năng thay thế thiết bị tách truyền thống đã được sử dụng hơn một thế kỷ qua. Nó cũng thú vị đối với các công ty dầu khí trong những năm gần đầy vì ảnh hưởng của giá dầu thế giới. Tuy nhiên, hành vi của các pha trong thiết bị rất nhanh, phức tạp và không ổn định gây khó khăn trong việc nâng cao hiệu suất tách pha. Nhiều nghiên cứu chứng minh rằng hình học và số lượng đầu vào là yếu tố quan trọng nhất ảnh hưởng trực tiếp đến hiệu suất phân tách các pha của thiết bị. Mục tiêu chính của nghiên cứu này là tìm hiểu sâu vể tác động của các cấu trúc hình học khác nhau của đầu vào hình vuông đối với động học và hiệu quả tách pha của hỗn hợp dòng 2 pha (không khí-nước). Hai cấu hình đầu vào khác nhau được xây dựng, cu thể là: Một đầu vào hình vuông với vòi phun giảm dần và hai đầu vào hình vuông đối xứng với vòi phun giảm dần. Từ kết quả đạt được, chúng tôi đề xuất sử dụng kiểu hai đầu vào hình vuông đối xứng để nâng cao hiệu quả phân tách các pha. Ngoài ra, nghiên cứu này có thể được xem như một bước đệm để tối ưu hóa các thông số hình học của GLCC trong những nghiên cứu tiếp theo.

Từ khoá: Thiết bị tách lỏng-khí, GLCC, Cyclone tách, dòng đa pha
${ }^{1}$ Trương Đại học Sui phạm Kỹ thuật TP.HCM

${ }^{2} P T N$ Trọng diêm Điều khiển số và Kỹ thuật Hệ thống, Khoa Cơ khí, Trương ĐHBK, ĐHQG-HCM (DCSELAB)

${ }^{3}$ Truờng Đại học Công nghiệp Thực phẩm TP.HCM

Liên hệ

Nguyễn Thanh Nam, PTN Trọng điểm Điều khiển số và Kỹ thuật Hệ thống, Khoa Cơ khí, Trường ĐHBK, ĐHQG-HCM (DCSELAB)

Email: thanhnam@dcselab.edu.vn

Lịch sử

- Ngày nhận: 15/10/2018

- Ngày chấp nhận: 27/12/2018

• Ngày đăng: 31/12/2019

DOI : 10.32508/stdjet.v3iSI1.731

\section{Check for updates}

\section{Bản quyền}

(c) ĐHQG Tp.HCM. Đây là bài báo công bố mơ được phát hành theo các điều khoản của the Creative Commons Attribution 4.0

International license.

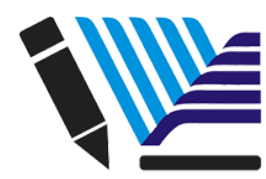

VNU-HCM Press
Trích dẫn bài báo này: Kha $\mathrm{H} M, \operatorname{Nam} \mathrm{N} T$, Tuyển $\mathrm{V}$, Ken $\mathrm{N}$ T. Nghiên cứu thực nghiệm về ảnh hưởng của đầu vào hình vuông ảnh hưởng đến hiệu suất của bộ tách lỏng-khí GLCC. Sci. Tech. Dev. J. - Eng. Tech.; 2(SI1):SI127-SI136. 